\title{
O GEPEM e a Formação de Professores: 40 Anos de Atuação
}

\author{
Rosana de Oliveira \\ Universidade do Estado do Rio de Janeiro (EDU/UERJ) \\ rosanaol40@yahoo.com.br
}

Neiva Ferreira Alves

Secretaria Estadual de Educação do Rio de Janeiro (SEEDUC/RJ)

neivalves@yahoo.com.br

\section{Nádia Estelino Ferraz}

Universidade do Estado do Rio de Janeiro (EDU/UERJ)

nadiaeferraz@hotmail.com

\begin{abstract}
Resumo
Este artigo é mais uma iniciativa do registro da história do GEPEM. Seu objetivo é apresentar um relatório sobre a comemoração dos 40 anos do GEPEM, que aconteceu no âmbito da realização do II Seminário em Educação Matemática: Formação de Professores, contextualizando historicamente o GEPEM e o seu percurso através das publicações. Além disso, prestamos uma singela homenagem à Professora Estela Kaufman Fainguelernt. Para concluirmos, apresentamos uma reflexão sobre a importância dos eventos na formação de professores com depoimento de alguns participantes.
\end{abstract}

Palavras-chave: GEPEM. Formação de Professores. Educação Matemática. Divulgação Científica.

\section{The GEPEM and Teacher Education: 40 Years of Performance}

\begin{abstract}
This article is an initiative of the record of the history of GEPEM. Your objective is to present a report about the celebration of the 40th anniversary of GEPEM, that took place on the II Seminar in Mathematics Education: Teacher Education, historically contextualizing the GEPEM and its journey through the publications. In addition, we provide a simple tribute for Teacher Estela Kaufman Fainguelernt. For conclusion we present some participants' reflection concerning the importance of events in teacher education.
\end{abstract}

Keywords: GEPEM.Teacher Education. Mathematics Education. Science Communication. 


\section{Introdução}

Esse artigo é mais uma iniciativa do registro da história do GEPEM. Ao longo desses 40 anos (1976-2016), uma preocupação constante foi contar sua própria história e homenagear aqueles que contribuíram de forma ímpar para essa trajetória. O quadro a seguir procura traçar uma linha do tempo dessas comemorações.

Quadro 1 - Trajetória de boletins GEPEM referentes a eventos comemorativos.

\begin{tabular}{|c|c|c|c|}
\hline \multicolumn{2}{|c|}{ Ano } & Eventos/Ações & Registro \\
\hline 1976 & Ano 1 & Fundação do GEPEM & Estatuto do GEPEM: Boletim 48 \\
\hline 1886 & 10 anos & $\begin{array}{c}\text { Evento na USU: Seminário Interestadual de } \\
\text { Educação Matemática }\end{array}$ & Boletim 18 \\
\hline 1991 & 15 anos & $\begin{array}{c}\text { Palestra da Prof. Maria Laura Mouzinho, na II } \\
\text { semana de Matemática - USU }\end{array}$ & $\begin{array}{l}\text { Boletim } 48 \text { - O GEPEM: } \\
\text { Testemunho histórico }\end{array}$ \\
\hline 1996 & 20 anos & $\begin{array}{c}\text { Reedição do Boletim número } 1 \text { e do Binômio } \\
\text { Professor-aluno. }\end{array}$ & Boletim 1 - reedição \\
\hline 2001 & 25 anos & Artigo: 25 Anos do GEPEM & Boletim 39 \\
\hline 2003 & 27 anos & Mudança de Sede USU para UFRRJ & $\begin{array}{l}\text { Boletim } 42 \\
\text { Primeiro Boletim Temático }\end{array}$ \\
\hline 2006 & 30 anos & $\begin{array}{c}\text { Evento na UFRRJ: GEPEM } 30 \text { anos: Passado, } \\
\text { Presente e Futuro. }\end{array}$ & Boletim 48 e 49 \\
\hline 2011 & 35 anos & $\begin{array}{l}\text { Evento Colégio Pedro II (Centro): Histórias dos } \\
\qquad 35 \text { anos do GEPEM }\end{array}$ & Boletim 58 \\
\hline 2016 & 40 anos & $\begin{array}{l}\text { Evento na UERJ: II Seminário em Educação } \\
\text { Matemática: Formação de Professores - } \\
\text { Comemoração aos } 40 \text { anos do GEPEM }\end{array}$ & Boletim 68 \\
\hline
\end{tabular}

Fonte: Elaborado pelas autoras, 2016.

Figura 1 - Capas dos Boletins 39, 42, 48, 49 e 58.
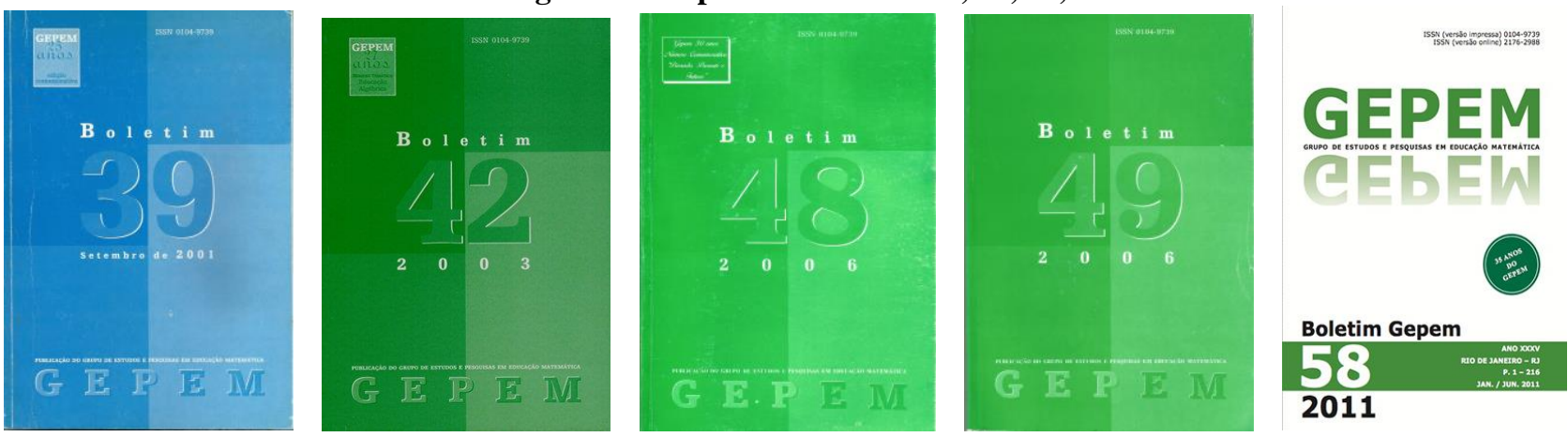

Fonte: Elaborada pelas autoras, 2016.

Em 24 de fevereiro de 1976, um grupo de 32 professores reuniu-se realizando a primeira Assembleia Geral do Grupo de Estudos e Pesquisas em Educação Matemática (GEPEM), na qual 
foi aprovado o estatuto elaborado por uma comissão que havia discutido em vários encontros anteriores, o que norteou a fundação do GEPEM e a eleição e posse da primeira diretoria do GEPEM para o biênio 1976/1977. Naquele momento, o objetivo era reunir um grupo de professores interessados em aprimorar o ensino de matemática, procurando conhecer e divulgar eventos internacionais e as pesquisas recentes na área de Educação Matemática existentes no exterior, além de divulgar ações desenvolvidas pelo GEPEM ou seus membros, como a organização de Seminários, Palestras, Mesas Redondas. Desde o início o grupo buscou atuar na Formação de Professores com um Curso de Iniciação Matemática para Professoras das primeiras séries do curso primário. Além da promoção de eventos, que visam uma maior divulgação sobre estudos e pesquisas em Educação Matemática, o Boletim GEPEM continua sendo publicado periodicamente, destinado a professores e pesquisadores de Matemática de todos os segmentos da Educação Básica e Superior e nas diversas modalidades de ensino, como EJA, EaD e outras. Conforme destaca Bairral (2006, p. 130), “[...] o Boletim GEPEM é uma publicação que objetiva contribuir para o progresso da Educação Matemática (nacional e internacional) e para a troca de experiências e ideias entre pesquisadores, educadores e professores de Matemática”.

O Boletim GEPEM sempre foi pioneiro na publicação de variados temas relacionados à Educação Matemática com ênfase na Formação de Professores. A partir do número 36, publicado no ano 2000, sob a presidência de Rosana de Oliveira, o boletim recebe um novo visual na capa, marcando uma nova fase, na qual houve a criação de novas seções cuja proposta foi conversar de forma mais aproximada com os professores, como: "Sugestão para sua aula" e "Notas de Aula" (CARNEIRO; REIS, 2000, p. 9-10).

Até o inicio de 2003, o GEPEM foi sediado na Universidade Santa Úrsula (USU), e a partir de 2003 passou a ser sediado na Faculdade de Educação da Universidade Federal Rural do Rio de Janeiro (UFRRJ), local em que se encontra até a presente data (julho/2016). Inaugurando a gestão da atual presidência, Marcelo Almeida Bairral (2003), no Boletim número 42, sugere uma nova mudança no visual da capa, incentivando novas publicações e mantendo o estudo da importância da formação inicial e continuada dos professores de Matemática.

Em 2006, Oliveira, Bairral e Reis, na edição comemorativa dos 30 Anos do GEPEM, divulgaram um minucioso mapeamento dos artigos publicados até o número 47, ressaltando a abrangência de temáticas envolvendo a Formação de Professores como interesse educativo. Referente ao bloco interesse educativo, a formação de professores, um dos investimentos do GEPEM, foi ratificada nas publicações. Somente em três números esta não foi explicitada em algum trabalho (OLIVEIRA; BAIRRAL; REIS, 2006). Silva, Barbosa e Kindel (2011) deram continuidade ao mapeamento no Boletim 57, considerando os fascículos de 49 a 56. 
Ao longo desses 40 anos, uma das principais atuações do GEPEM foi a publicação dos Boletins. Assim, já foram publicados 68 Boletins, sendo 63 em versão impressa, e, a partir do Boletim 36, também em versão online. No entanto, os anteriores do 1 ao 35 também são encontrados na página do GEPEM. A partir do número 63 sua publicação passou a ser apenas online $^{1}$. Manter a publicação do Boletim GEPEM durante todos esses anos é sem dúvida uma vitória, um motivo para comemorarmos.

\section{Seminário em Educação Matemática: Formação de Professores - Comemoração 40 anos GEPEM.}

O II Seminário em Educação Matemática: Formação de Professores em Comemoração aos 40 anos do GEPEM realizou-se no dia 23 de junho de 2016, nas dependências da Faculdade de Educação da Universidade do Estado do Rio de Janeiro (UERJ) - Campus Maracanã. Esse evento se insere no Projeto de Extensão Formação de Professores e Divulgação Científica em Educação Matemática e foi organizado em parceria com a diretoria do GEPEM. O evento foi gratuito e contou com cerca de quase 80 inscritos, dos quais 50 compareceram. Foram oferecidas quatro oficinas, sendo duas pela manhã e duas à tarde. Ao final do dia, em homenagem à professora Estela Kaufman Fainguelernt, foram ministradas duas palestras, além da exposição de pôsteres. O quadro a seguir descreve os títulos das oficinas, seus ministrantes e os títulos das palestras.

Quadro 2: Atividades do II Seminário em Educação Matemática: Formação de Professores

\begin{tabular}{|c|c|c|}
\hline \multicolumn{3}{|c|}{ OFICINAS } \\
\hline & Títulos & Ministrantes \\
\hline 1 & $\begin{array}{l}\text { Os Livros Didáticos de Matemática } \\
\text { mudaram? }\end{array}$ & Denise Medina - EDU/UERJ \\
\hline 2 & Simetria e Visualização com Tangram & Dora Soraia Kindel- IM/UFRRJ \\
\hline 3 & $\begin{array}{l}\text { De papel e lápis ao uso de smartphones: como } \\
\text { podemos melhorar o aprendizado matemático } \\
\text { dos alunos? }\end{array}$ & $\begin{array}{l}\text { Marcelo Bairral, UFRRJ; } \\
\text { Wagner Marques, UCAM, } \\
\text { FAETEC e UFRRJ/PPGEduc; } \\
\text { João Carlos Barreira, UFRRJ/IC } \\
\text { e Elen Roza, UFRRJ/IC }\end{array}$ \\
\hline 4 & Blocos Lógicos: do jogo a generalização & $\begin{array}{l}\text { Rosana de Oliveira } \\
\text { (EDU/UERJ) e Nádia Estelino } \\
\text { Ferraz (EDU/UERJ) }\end{array}$ \\
\hline \multicolumn{3}{|c|}{ PALESTRAS } \\
\hline 1 & $\begin{array}{l}\text { Algumas das contribuições da Prof }{ }^{a} \text { Estela } \\
\text { Kaufman Fainguelernt para o ensino da }\end{array}$ & $\begin{array}{l}\text { Marcelo Ferreira Martins } \\
\text { Salvador (Colégio Stockler e }\end{array}$ \\
\hline
\end{tabular}

\footnotetext{
${ }^{1}$ Todos os boletins podem ser encontrados no endereço: http://www.ufrrj.br/SEER/index.php?journal=gepem\&page=index
} 


\begin{tabular}{|c|l|l|}
\hline & geometria. & EMPP) \\
\hline 2 & $\begin{array}{l}\text { Estela e o projeto Fazendo arte com a } \\
\text { matemática. }\end{array}$ & $\begin{array}{l}\text { Katia Regina Ashton Nunes } \\
\text { (Associação Educacional } \\
\text { Miraflores, Niterói/RJ) }\end{array}$ \\
\hline
\end{tabular}

Fonte: Elaborado pelas autoras, 2016.

A seguir apresentamos um breve resumo das atividades realizadas ilustradas com fotos.

\section{Oficina 1: Os Livros Didáticos de Matemática mudaram?}

A oficina teve como objetivo desenvolver uma reflexão sobre o uso de livros didáticos de Matemática como fontes para a pesquisa, aguçando a curiosidade, criatividade e capacidade de reflexão e análise. Visou responder às seguintes questões: Quais mudanças você observa nos livros didáticos para o ensino de matemática? Como utilizar livros didáticos para investigar o trajeto histórico da educação matemática?

\section{Figura 2 - Foto da Oficina 1: Os participantes usam máscaras e luvas como pré-requisito para manipularem livros antigos.}

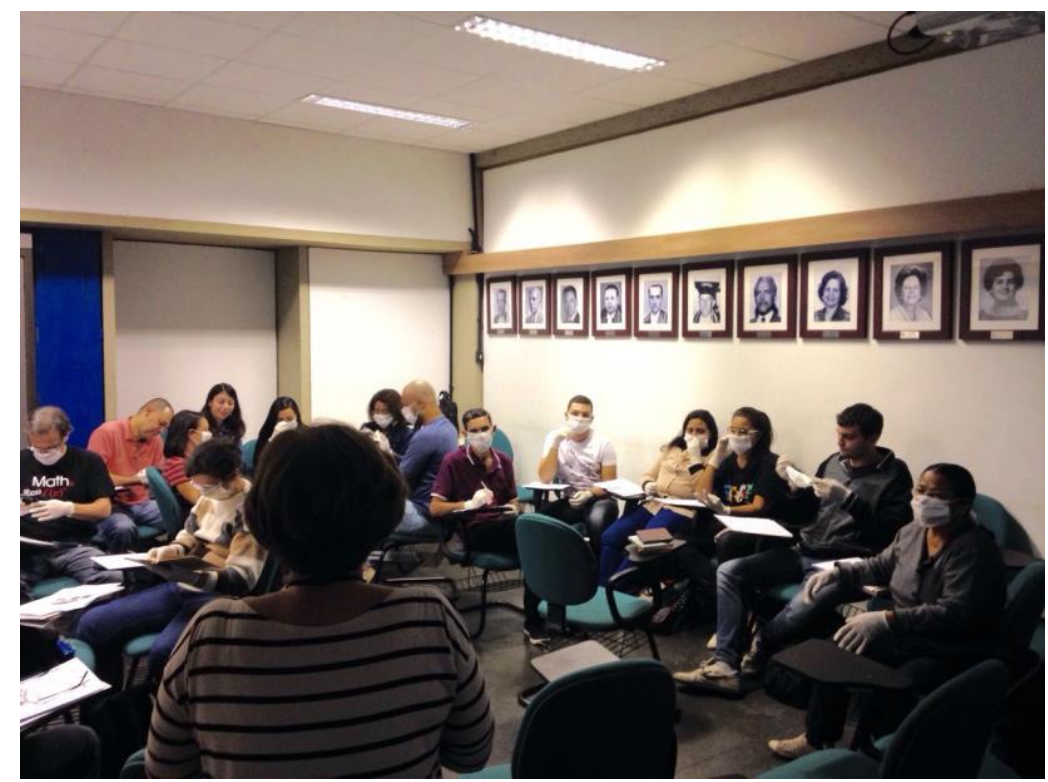

Fonte: Elaborada pelas autoras, 2016.

\section{Oficina 2: Simetria e Visualização com Tangram.}

O objetivo dessa oficina concentrou-se em trabalhar com tarefas que orientam os estudantes na exploração de simetria axial, reflexão ou espelhamento de figuras geométricas, usando peças do Tangram quadrado tradicional. Em algumas tarefas utilizaram-se apenas as sete peças de um único Tangram; em outras foram necessários dois jogos de Tangram. 
Figura 3 - Foto da Oficina 2: Professora Dora Soraia Kindel, debate com os participantes sobre as tarefas propostas.

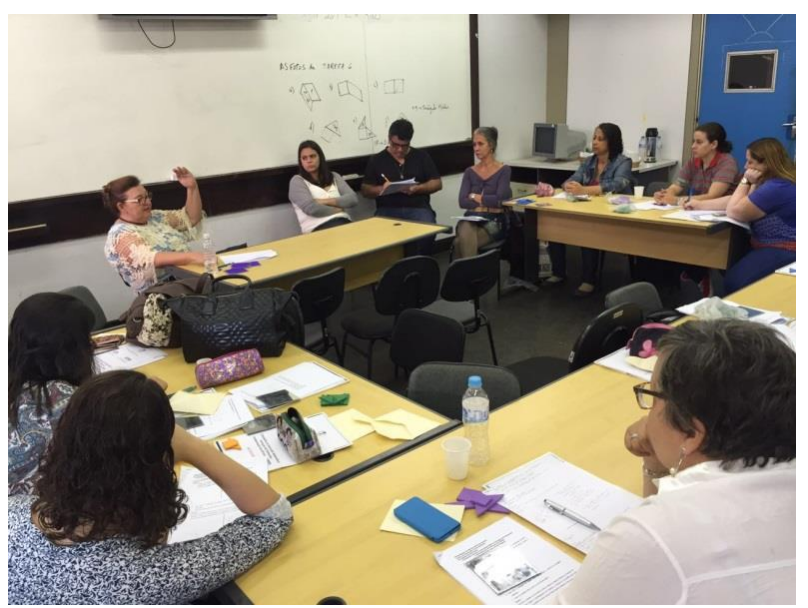

Fonte: Elaborada pelas autoras, 2016

Oficina 3: De papel e lápis ao uso de smartphones: como podemos melhorar o aprendizado matemático dos alunos?

Desenvolver conceitos a partir de diferentes recursos e da própria reflexão em aula deve ser um dos propósitos do ensino. Nessa oficina, mediante um circuito de atividades com o uso de diferentes materiais (Tangram Quadrado, geoplano, palitos para picolé e para churrasco, FreeGeo App, barbante), oportunizou-se aos participantes vivenciarem e discutirem com o coletivo o seu aprendizado e o seu desenvolvimento conceitual sobre polígonos.

Figura 4 - Foto da Oficina 3: Professor Marcelo Bairral (em pé de costas) e o professor Wagner Marques (em pé de blusa verde) interagem com os pequenos grupos.

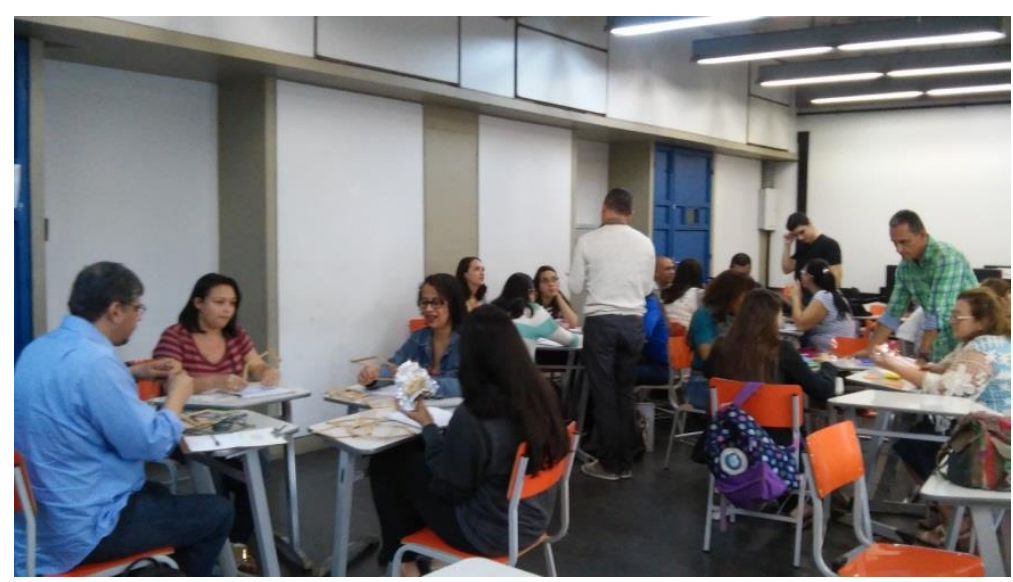

Fonte: Elaborada pelas autoras, 2016.

Oficina 4: Blocos Lógicos: do jogo a generalização.

Os Blocos Lógicos de Dienes possuem vasta aplicação no ensino de matemática nos anos iniciais do Ensino Fundamental, mas através da compreensão de sua estrutura, pode-se conduzir a pensamentos matemáticos mais avançados. O objetivo específico dessa oficina foi partir de um jogo 
para compreensão dos atributos e valores, e identificar a estrutura multiplicativa, refletindo sobre a possibilidade de criar novos materiais relacionados à estrutura dos Blocos Lógicos.

Figura 5 - Foto da Oficina 4: A professora Rosana de Oliveira explica a proposta da tarefa com uso de tabela de dupla entrada e Nádia Ferraz (em pé) contribui na dinamização dos pequenos grupos.

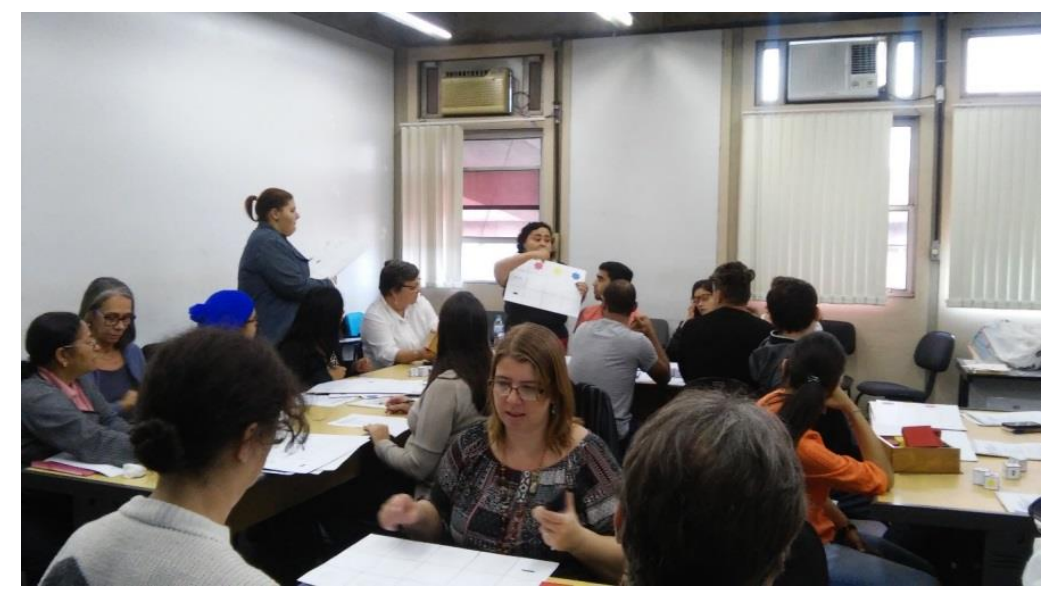

Fonte: Elaborada pelas autoras, 2016.

\section{Homenagem à Professora Estela Kaufman Fainguelernt}

No aniversário de 40 anos do GEPEM rendemos nossa singela homenagem à Prof ${ }^{a}$ Estela Kaufman Fainguelernt. Sua dedicação à área de Educação Matemática foi registrada por Silva, Barbosa e Kindel (2011, p. 171):

[...] Estela Kaufman Fainguelernt, presidente de 1990 a 1996, dirigiu o curso de mestrado em Educação Matemática da Universidade Santa Úrsula (USU), criado em parceria com o GEPEM. Neste curso, a professora Estela não só participou de forma atuante na criação, mas, principalmente, na sua consolidação por meio de suas sucessivas diretorias.

Para homenagem no evento, convidamos o Prof. Marcelo Salvador e a Prof ${ }^{a}$ Kátia Nunes para proferirem palestras em sua homenagem, pois esses professores tiveram a oportunidade de trabalhar de forma mais próxima à professora.

O professor Marcelo Ferreira Martins Salvador nos brindou com a palestra Algumas das contribuições da Prof ${ }^{a}$ Estela Kaufman Fainguelernt para o ensino da geometria, que tomou como base sua dissertação intitulada "Uma história de paixão: Estela Kaufman Fainguelernt e o ensino da Geometria”, em que ele afirma:

[...] que teve como objetivo geral levantar vestígios na formação matemática e na prática docente de uma professora, a fim de sinalizar o que a impulsionou a centrar sua docência e produção na área da Geometria. [...] Dentre eles, temos: obras publicadas e outras produções que contam com sua autoria, depoimentos orais dela e de pessoas que trabalharam junto à Estela, além de cerca de dois mil e 
quatrocentos documentos com os registros que estão constituindo atualmente o Arquivo Pessoal Estela Kaufman Fainguelernt (APEKF)².” (SALVADOR, 2012)

Figura 6 - Foto da Palestra 1 - Prof. Marcelo Ferreira Martins Salvador e os participantes do evento

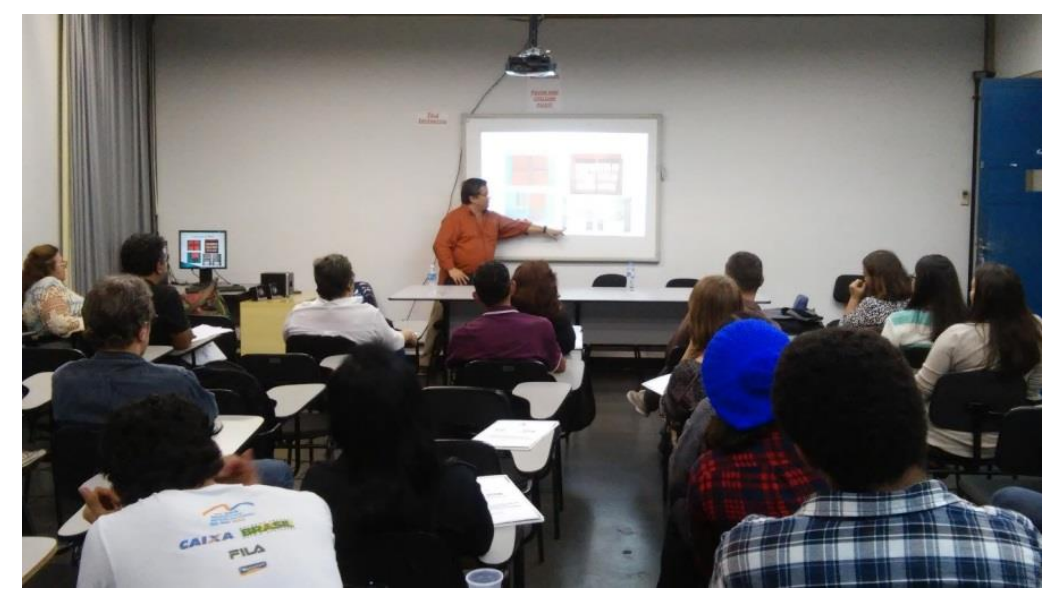

Fonte: Elaborada pelas autoras, 2016.

A professora Katia Regina Ashton Nunes contribuiu de forma apaixonada com sua palestra "Estela e o projeto Fazendo arte com a matemática". A educadora ilustrou de forma exemplar com sua prática pedagógica com os estudantes da escola que coordena. Sobre sua relação com Estela, ela afirma que:

[...] a partir de 2000, ela se tornou muito mais que minha mestra inspiradora e companheira de trabalhos ou viagens. Tive a felicidade e o privilégio de conviver com ela como amiga, participar de seu dia a dia, de suas conquistas e de grandes sonhos. Como a professora maluquinha de Ziraldo, Estela tinha estrelas no lugar do olhar e, do alto dos seus 80 anos, conquistava a todos com sua alegria, dedicação, competência, paixão e grande vitalidade. Ela deixa um legado inestimável para quem se dedica à educação matemática. (NUNES, 2016)

Figura 7 - Foto da Palestra 2: Prof $f^{a}$ Katia Regina Ashton Nunes, os participantes do evento e os pôsteres em homenagem a Prof ${ }^{\text {a }}$ Estela, gentilmente cedidos pelo Prof. Paulo Colonese.

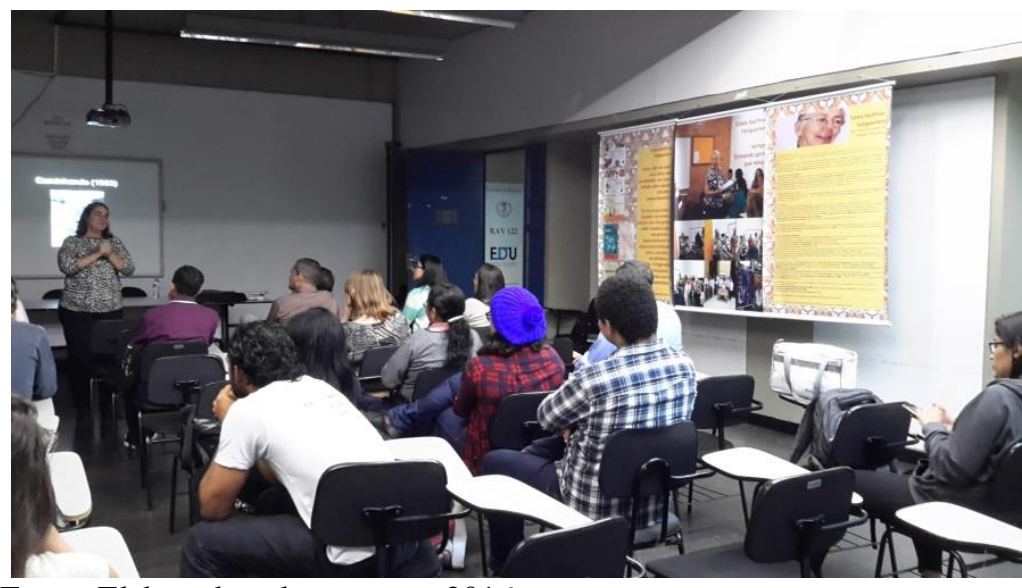

Fonte: Elaborada pelas autoras, 2016.

\footnotetext{
${ }^{2}$ Em 04 de julho de 2016 o APEKF foi doado ao Museu de Astronomia e Ciências Afins (MAST), onde também ocorreu um momento comemorativo. O MAST fica localizado no bairro de São Cristóvão, na cidade do Rio de Janeiro.
} 
Figura 8 - Livros da professora Estela em parceria com a professora Kátia Nunes
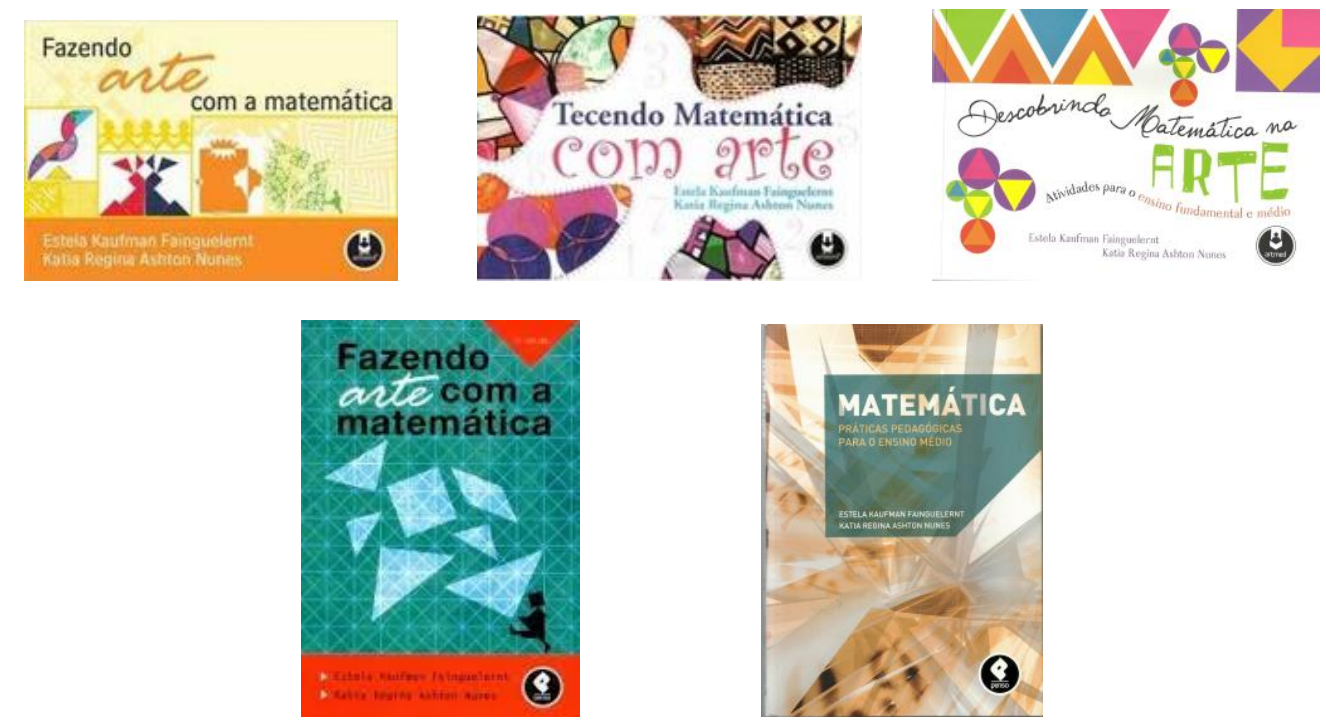

Fonte: Elaborada pelas autoras, 2016.

\section{A Formação de Professores Através da Promoção e Participação em Eventos.}

Os eventos na área de Educação Matemática ocupam importante papel na divulgação científica e troca de experiências entre professores em serviço e licenciandos. O estatuto do GEPEM (2006, p. 137), de 24 de fevereiro de 1976, já apontava essa ação como uma de suas finalidades.

[...] Art. $2^{\circ}$ : O GEPEM tem a finalidade de congregar todos os interessados em Educação Matemática (EM), estimular e manter, um interesse ativo pela Matemática e suas aplicações, incentivar a pesquisa, manter atualizado o conhecimento de Matemática dos professores e criar, por todos os meios ao seu alcance, as condições necessárias para o desenvolvimento da Educação Matemática.

Parágrafo Único - para melhor consecução dos seus fins, o GEPEM poderá: [...]

a) Promover congressos, seminários, reuniões científicas, cursos e outras atividades análogas, destinadas a difundir e aperfeiçoar a Educação Matemática. ${ }^{3}$

Um trabalho relevante, citado em diferentes momentos pela Prof ${ }^{a}$ Maria Laura Mouzinho Leite Lopes e Prof ${ }^{a}$ Moema Sá Carvalho, foi a pesquisa realizada pelo grupo em 1978-1979, sobre professoras primárias (anos iniciais do Ensino Fundamental) de escolas particulares das zonas sul e norte do Rio de Janeiro. Esse trabalho foi divulgado no Boletim 11, denominado de Binômio Professor x Aluno (CARVALHO, 1996).

Assim, o GEPEM, ao longo de sua história, promoveu eventos, cursos de extensão e Curso de Especialização na Universidade Santa Úrsula (USU) que deu origem ao Mestrado em Educação Matemática. Um número significativo de mestres, oriundos daquele Programa, ocupam lugares de destaque nas principais instituições públicas do Estado do Rio de Janeiro, além de exercerem com compromisso e qualidade acadêmica a docência em diferentes níveis de ensino.

\footnotetext{
${ }^{3}$ Grifo nosso
} 
[...] O mestrado em Educação Matemática sob a direção da professora Estela contou com pesquisadores de diferentes lugares do mundo, formou diversos Educadores Matemáticos no estado do Rio de Janeiro e, muitos destes, continuam realizando pesquisas na área em diferentes instituições de ensino. (SILVA; BARBOSA; KINDEL, 2011, p. 171)

Os eventos na área de Educação Matemática hoje de diferentes portes, locais, nacionais e internacionais, cresceram significativamente nos últimos 40 anos. Suas finalidades diferem entre alguns mais voltados para a pesquisa acadêmica (SIPEM, EBRAPEM), nos quais o público é majoritariamente formado por professores participantes de programas de pós-graduação, mestrandos e doutorandos, e outros que se destinam a difundir metodologias e pesquisas (EEMAT, ENEM) com a participação de licenciandos em matemática e pedagogia e professores que já atuam na Educação Básica. Essa distinção não possui limites rígidos, ou seja, os objetivos podem se entrecruzar. $\mathrm{O}$ evento que referenciamos neste texto, insere-se na formação inicial e continuada de professores que se encontram em sala de aula. Identificamos diferentes motivações e objetivos dos participantes nos eventos, e pelas suas avaliações acreditamos que vale à pena continuar organizando eventos destinados à formação de professores. A seguir apresentamos alguns desses depoimentos.

Figura 9 - Depoimento do Participante A

Oficina 1: Livros didáticos mudaram?... Eu gostei muito da oficina, atendeu sim o que eu esperava. É meio estranho mas, de certa forma, eu gostei da realização do evento mesmo com a greve pois são raros os casos que professores liberem ou apoiem os alunos a participarem de seminários ou outros eventos por conta do horário das disciplinas. Acho válido se discutido isso entre os professores pois tem muitas alunos que dividem realidades parecidas com a minha... só estou pela manhã na UERJ pois trabalho no período da tarde. Devemos pensar também em divulgação desses eventos, muitas vezes passam despercebidos, e o pior, as vezes do lado da nossa sala de aula. Gostei muito e esnern narticinar de outros!!

Fonte: Elaborada pelas autoras, 2016.

Figura 10 - Depoimento do Participante B

Parabéns pelo evento e pelo trabalho hercúleo de organizar alguma coisa nesse Estado que não dá valor ao empenho de professores. Reconhece nossa força e por isso faz de tudo para acabar com nossos direitos. Eventos como esses que congregam professores e licenciandos servem para nós alimentarmos de coragem e continuar nossa luta pela educação de qualidade e inovadora. Quanto as oficinas, avalio como excelentes pelo material oferecido e pela qualidade das professoras. Professora Soraia Kindel é muito atuante e sempre está envolvida em questões para dinamizar o ensino em matemática, principalmente para futuros professores. Professora Rosana é meu exemplo de mulher desbravadora e independente, principalmente por manter em uma universidade pública um núcleo que investiga a educação e não quer parar no tempo. Na oficina soube valorizar um material tradicional, mas destacou a importância de sua utilização em um tempo que se valoriza a tecnologia digital não levando em conta o desenvolvimento do raciocínio para o entendimento de como funciona ou como se faz. Cria um mundo de usuário e não produtores. Parabéns por garantir a qualidade de um evento que congregam profissionais da educação.

Fonte: Elaborada pelas autoras, 2016. 
Figura 11 - Depoimento do Participante C

Participei da oficina 2 e gostei muito, a proposta excelente, na qual já apliquei em sala de aula está semana. Tive imensa alegria e satisfação em participar do evento! Me senti como se tivesse voltado aos tempos de faculdade! Fiz minha licenciatura em Matemática aí na Uerj e me formei em 1988! Fiz parte do Gepem, como sócia, na época. Vcs fizeram um trabalho admirável! A Oficina de Tangram foi perfeita! Revi vários conceitos, principalmente sobre o meu papel de educadora! Parabéns à Soraya! A Oficina do Bairral, também foi impecável! Já vou usar o FreeGeo com meus alunos! As palestras foram excelentes! Fiquei muito entusiasmada com o trabalho da Katia Nunes em parceria com a Prof Estela! Parabéns a todos e muito obrigada!

Fonte: Elaborada pelas autoras, 2016.

A formação de professores que ensinam matemática continua sendo uma preocupação de vários pesquisadores na área de Educação Matemática e o GEPEM, ao longo de sua trajetória, tem contribuído para essa formação. Esperamos com este texto ter atendido nosso objetivo de contribuir com mais um registro histórico do percurso do GEPEM. Apontamos como uma demanda para próximos números a análise dos artigos publicados nos Boletins posteriores ao número 56.

\section{Referências}

BAIRRAL, M. A. Atividades desenvolvidas pela Diretoria do GEPEM no período 2003-2006. Boletim GEPEM, Rio de Janeiro, n. 48, p. 125-136, 2006.

CARNEIRO, J. P.; REIS, R. M. Editorial. Boletim GEPEM, Rio de Janeiro, n.36, p. 9-10, 2000.

CARVALHO, M. S. Binômio professor-aluno na iniciação à educação matemática. Boletim GEPEM, Rio de Janeiro, n.11, p. 1-50, 1980.

ESTATUTO DO GEPEM. Boletim GEPEM, Rio de Janeiro, n. 48, p. 137-144, 2006.

NUNES, K. R. A.. Dedicação e brilhantismo. Revista Pátio, Porto Alegre, n.77, 2016. Disponível em http://loja.grupoa.com.br/revista-patio/artigo/12279/dedicacao-e-brilhantismo.aspx Acesso em 06 de julho de 2016.

OLIVEIRA, R., BAIRRAL, M. A. e REIS, R. M. M. Um estudo sobre a Educação Matemática publicada nos 30 anos de Boletim GEPEM. Boletim GEPEM, Rio de Janeiro, n. 48, p. 23-84, 2006.

SALVADOR, M. F. M. Uma história de paixão: Estela Kaufman Fainguelernt e o ensino de geometria, 2012. XIV, 71f.; il.; 29,7cm. Dissertação (Mestrado Profissional em Educação Matemática) - Universidade Severino Sombra, Vassouras, 2012. Disponível em https://repositorio.ufsc.br/xmlui/handle/123456789/134648 . Acesso 07 de julho de 2016.

SILVA, A. L. V.; BARBOSA, A. C. M.; KINDEL, D. S. GEPEM 35 anos: depoimentos e ações que narram e registram sua história. Boletim GEPEM, Rio de Janeiro, n.58, p. 167-201, 2011. 